\title{
Familial skeletal cardiovascular syndrome (Holt-Oram) in a polygamous African family
}

\author{
Asuquo U. Antia \\ From the Department of Paediatrics, University College Hospital, Ibadan, Nigeria
}

A polygamous Nigerian family with inherited skeletal cardiovascular anomalies (Holt-Oram syndrome) is described. Common to the affected individuals in this family were pectus excavatum and abnormalities of the thumbs. Atrial septal defect was proven by angiocardiography in one and clinically diagnosed in another member of the family. The mode of inheritance of the abnormalities in this family as in other reported cases is thought to be an autosomal dominant type which is unaffected by the polygamous situation.

Association of congenital skeletal anomalies and cardiovaseular malformations occurring in a number of Caucasian families has been previously described (Holt and Oram, 1960; McKusick, I96I ; Zetterqvist, 1963; Pruzanski, 1964; Holmes, 1965; Lewis et al., Received I August 1969.
I965; Gellis and Feingold, I966; Chang, 1967). Studies of pedigrees in the reported cases suggest an autosomal dominant type of inheritance. To our knowledge the present studies of this syndrome in a polygamous Nigerian family represent the first to be reported in the African. The studies further

FIG. I Pedigree of family with skeletal-cardiovascular syndrome.

1

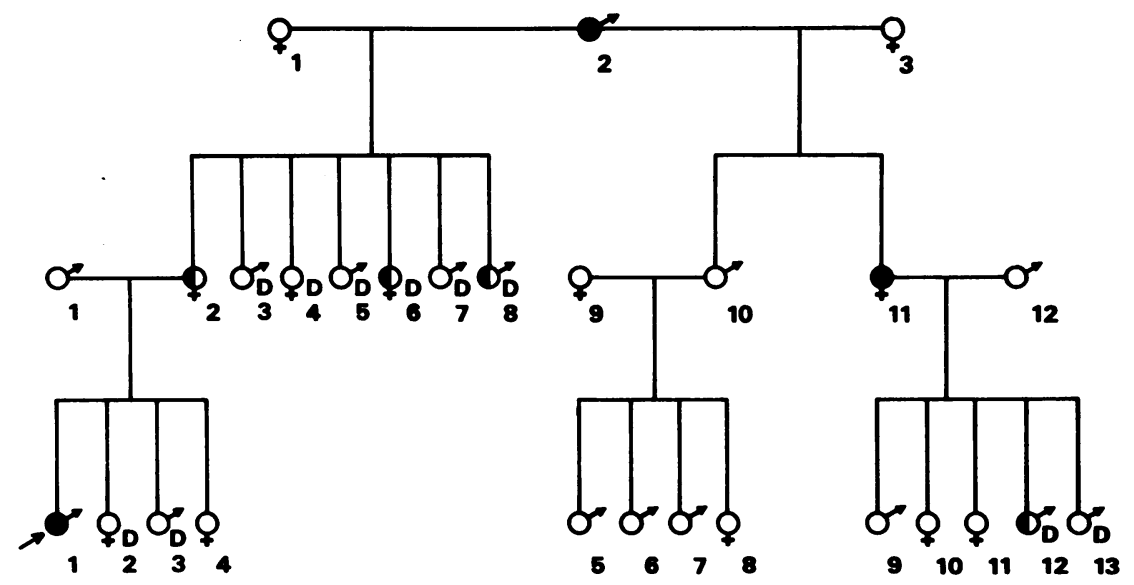

III

1234

SKELETAL AND CARDIOVASCULAR ANOMALIES

(1) SKeletal anomalies

- $\sigma^{\circ}$ NORMAL

D DEAD

PROPOSITUS 


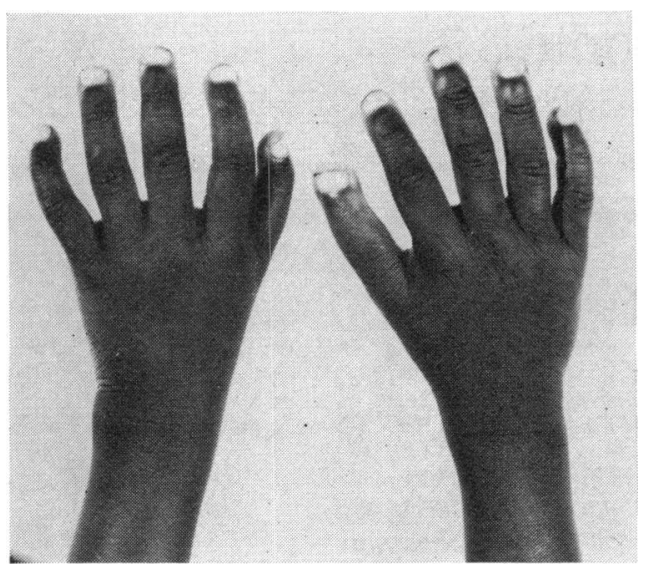

FI G. 2 Hands of the propositus (Case I) showing the abnormalities of the thumbs and little fingers.

confirm the suggested mode of inheritance, i.e. an autosomal dominant, which as expected is unaffected by the polygamous situation. Though the skeletal anomalies are common in the upper extremities and are emphasized in previous communications, the present report draws attention to the equally common anomaly of the sternum.

\section{The family}

The pedigree of the family studied is shown in Fig. I. The grandfather (I.2) of the propositus III.I and all the living members in generations II and III were examined by the author. The histories were obtained from the grandfather, the two living daughters II.2 and II, and the only living son II.ro. The examination included physical evaluation, $x$-rays of the chest and upper extremities, and electrocardiogram. Angiocardiography was carried out in the propositus. No information was available regarding the cardiovascular status of the dead members of the family II.6 and 8, and III.12, who are said to have had conspicuous deformities of the hands. Death occurred in these children at birth, and at the age of 6 months, respectively in II.6 and 8, and at the age of I week in III.12. No necropsy was carried out on any of these infants. The case reports which follow concern the propositus (III.I), his mother (II.2), an aunt (II.II), and the grandfather (I.2).

\section{Case reports}

Case I. (III.1). This propositus, a $4 \frac{1}{2}$-year-old boy, was referred to University College Hospital (UCH No. 207337) on account of recurrent epistaxis for two years. The recent episode was preceded by fever which lasted for a week. On physical examination he weighed only $14.6 \mathrm{~kg}$. The epistaxis was caused by vessels in the nasal

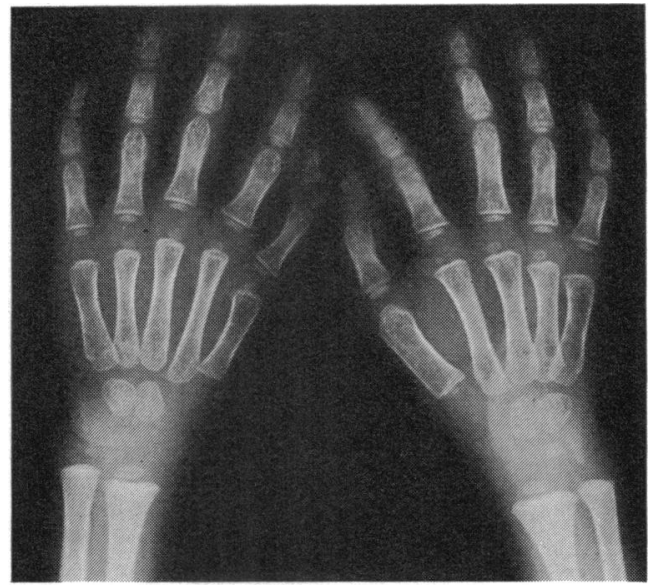

FIG. 3 X-ray of the hands (Case I). Note rudimentary intermediate phalanx left thumb. The phalanges in the right thumb are larger than normal.

septum; these were cauterized. Examination of the musculo-skeletal system showed moderate pectus excavatum. There was some wasting of the thenar and hypothenar muscles of both hands. The right thumb was slightly bigger than the left. Both thumbs were finger-like in shape and in the same plane as the fingers. There was incurving of both little fingers and the left thumb (Fig. 2). In the cardiovascular system, the peripheral pulses were regular, equal, and of good volume. Blood pressure measured $110 / 70 \mathrm{~mm}$. $\mathrm{Hg}$ in both arms. There was a right ventricular thrust. Apex beat was in the 5th left intercostal space, $9 \mathrm{~cm}$. from the midline. There were no thrills. Pulmonary valve closure sound was accentuated and widely split, the splitting being unaffected by respiration. There was a grade 2-3/6 mid-systolic murmur maximum in the pulmonary area, but widely transmitted to the back and both axillae. Diastole was clear. Radiograph of the hands showed a rudimentary intermediate phalanx in the left thumb and larger than normal phalanges in the right thumb (Fig. 3). The rest of the skeletal system was normal. Chest $x$-ray with barium swallow revealed moderate cardiac enlargement, prominence of the pulmonary artery segment, and increased lung vascularity.

Electrocardiogram showed sinus rhythm, QRS frontal axis $+120^{\circ}$, and right ventricular hypertrophy. Angiocardiography showed atrial septal defect. Other investigations included $\mathrm{Hb}$ I I $\circ \mathrm{g}$./ roo $\mathrm{ml}$. ( $75 \%$ ), PCV 34 per cent, and $\mathrm{Hb}$ genotype AS.

Case 2 (II.2). This was the mother of the propositus. She had no cardiovascular symptoms. Physical examination showed a moderate degree of pectus excavatum. No other abnormality was found either in the skeletal or cardiovascular system. Hb genotype was AS. 


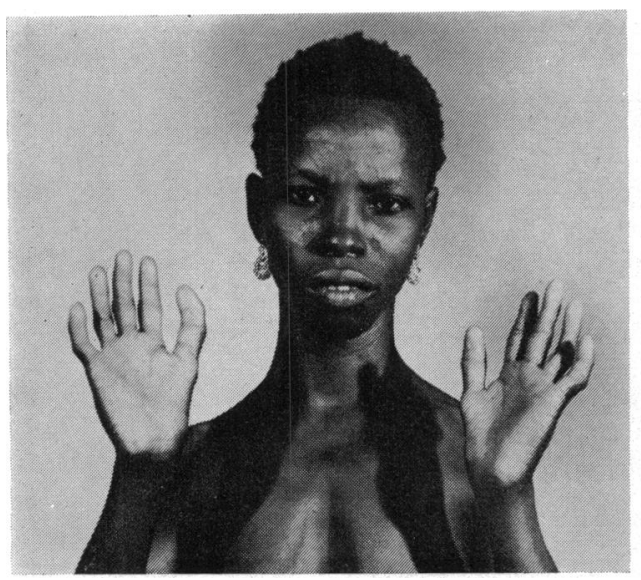

FIG. 4 Case 3. Note the elongated fingerlike thumbs lying in the same plane as the fingers.

Case 3 (II.II). Her father was the grandfather of the propositus. She had no cardiovascular symptoms. Physical examination revealed conspicuous pectus excavatum. Both thumbs were elongated and fingerlike (Fig. 4). The right thumb and the little fingers showed incurving. The thenar and hypothenar eminences were flattened. She could not fully extend the left elbow, and left supination and pronation were considerably limited. $X$-rays of the skeletal system showed three phalanges in both thumbs (Fig. 5), the intermediate phalanx in the left being smaller than the right. The right thumb was longer than the right little finger. There was partial fusion of the proximal parts of the left radius and ulna, and also deformity of the distal end of the left humerus; the olecranon fossae on both sides were shallow. Examination of the cardiovascular system revealed normal regular pulses. Blood pressure measured $120 / 90 \mathrm{~mm}$. Hg. The heart was enlarged clinically. No thrills were present. There was a grade 2 systolic murmur in the pulmonary area. Pulmonary valve closure sound was loud and widely split. The findings were suggestive of an atrial septal defect. The patient refused cardiac catheterization and angiocardiography.

Chest $x$-ray showed moderate cardiac enlargement, and increased vascularity in the lung fields. Electrocardiogram revealed sinus rhythm, normal frontal QRS axis, and normal QRS voltages. $\mathrm{Hb}$ genotype was AS.

Case 4 (I.2). This old man was the grandfather of the propositus. He married two wives each of whom had a daughter (Cases 2 and 3, respectively). He had no cardiovascular symptoms. On physical examination he had conspicuous pectus excavatum. The right thumb (Fig. 6) was fingerlike and curved inwards; the left thumb was diminutive. There was flattening of the thenar and hypothenar eminences in both hands. $\mathrm{He}$

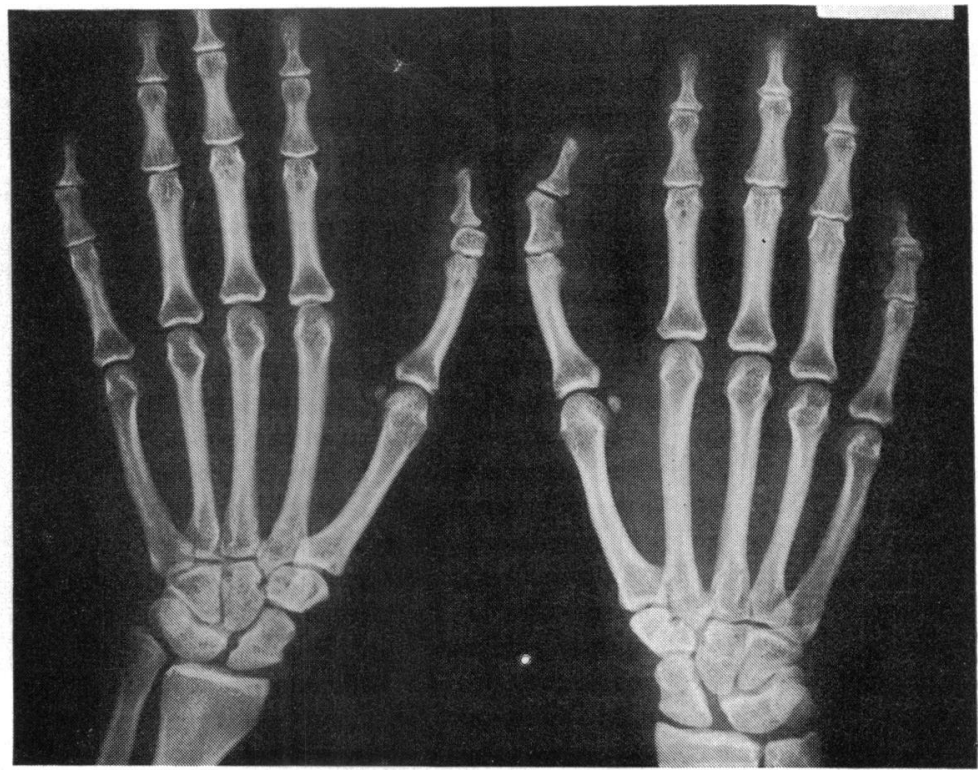

FIG. 5 Case 3. X-ray of hands showing

three phalanges in each thumb.

could not fully supinate or pronate the left arm, and extension at the left elbow was conspicuously limited. The left upper arm was smaller than the right. $X$-rays of the hands showed three phalanges in both thumbs, and fusion of the left scaphoid and lunate (Fig. 7). The left humerus was smaller than the right, and the left olecranon fossa was shallow. Examination of the heart revealed an irregular pulse, rate 60 a minute. Blood pressure was $120 / 80 \mathrm{~mm}$. $\mathrm{Hg}(\mathrm{RA}), 130 / 80 \mathrm{~mm}$. $\mathrm{Hg}$ (LA). There was no cardiac enlargement or murmur. The heart sounds were normal. Chest $x$-ray showed normal heart shadow and normal vascularity. Electrocardiogram revealed prolonged $P R$ interval $(0.28 \mathrm{sec}$.) and the rate 56 a minute. $\mathrm{Hb}$ genotype was AS.

\section{Discussion}

In 1960 Holt and Oram first reported a family in which 9 members in 4 generations had peculiar skeletal deformities affecting mainly the upper limbs, and congenital cardiac defects. The authors considered this an example of an inherited abnormality. Since the original report of the syndrome, other well-documented cases have been described in Caucasian families. The terms Holt-Oram (Zetterqvist, 1963; Pruzanski, 1964; Gellis and Feingold, 1966; Chang, 1967) and upper limb cardiovascular syndromes (Lewis et al., 1965) have been suggested for these skeletal cardiovascular anomalies. The latter term seems inappropriate since the skeletal anomalies, though 


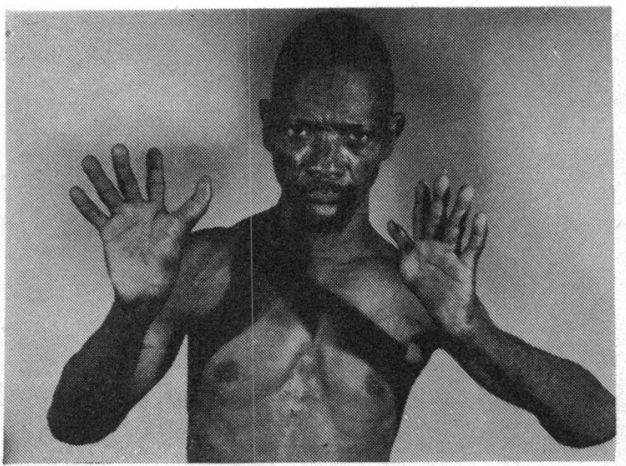

FIG. 6 Case 4. The right thumb is fingerlike and is larger than the left. Note also the abnormality of the palms.

affecting mainly the upper extremities, involve other bones as well - the sternum in particular, the palate, the clavicle, and the vertebrae (Holt and Oram, 1960; Holmes, 1965; Lewis et al., 1965). However, the syndrome consists essentially of inherited anomalies of the musculo-skeletal system and a spectrum of congenital heart defects, the most common being secundum type atrial septal defect. The Nigerian family which forms the basis of the present report exhibits most of the anomalies already described. The anomalies in the thumbs were identical in the father and daughter; pectus excavatum was present in all four cases. Clinically two of the four members of the family had evidence of atrial septal defect though this was proven by angiocardiography in one. The three members of the family who had anomalies of the fingers and died in infancy presumably had serious cardiac defects. Holmes (1965) found that the affected women tended to be far more seriously handicapped than the men. In the present study of the three affected female patients, one infant who died at the age of 6 months presumably had a serious cardiac defect; the remaining two were not seriously affected. The mother of the propositus had only pectus excavatum.

The mode of inheritance in the present family as well as in the previously reported cases appears to be an autosomal dominant type. The skeletal and cardiovascular abnormalities are presumably caused by a single gene or gene complex. In the present family the fact that the grandfather of the propositus is a polygamist does not affect this mode of inheritance, because he himself carries the gene, and, therefore, with every child that he fathers there would be one

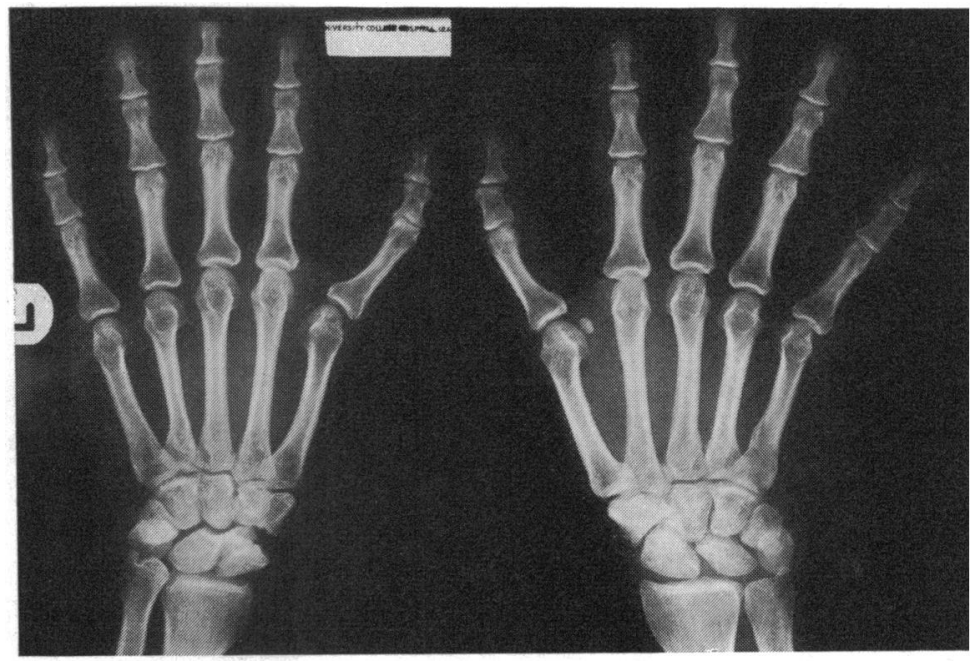

FIG. 7 Case 4. X-ray of the hands showing three phalanges in each thumb.

chance in two on the average that he will pass on the gene to the offspring regardless of whether or not the child is borne by the same woman.

I wish to thank Professor P. E. Polani and Dr. J. Fraser Roberts, Paediatrics Research Unit, Guy's Hospital Medical School, London, and Professor L. Luzzatto, Department of Haematology, University College Hospital, Ibadan, Nigeria, for their help in the genetic aspect of the study.

\section{References}

Chang, C. H. (1967). Holt-Oram syndrome. Radiology, 88, 479.

Gellis, S. S., and Feingold, M. (1966). Holt-Oram syndrome. American fournal of Diseases of Children, I12, 465.

Holmes, L. B. (1965). Congenital heart disease and upper-extremity deformities. New England fournal of Medicine, 272, 437.

Holt, M., and Oram, S. (1960). Familial heart disease with skeletal malformations. British Heart fournal, 22, 236.

Lewis, K. B., Bruce, R. A., Baum, D., and Motulsky, A. G. (1965). The upper limb-cardiovascular syndrome. Fournal of the American Medical Association, 193, 1080.

McKusick, V. A. (I96I). Medical genetics, 1960. Fournal of Chronic Diseases, 14, 1.

Pruzanski, W. (I964). Familial congenital malformations of the heart and upper limbs: a syndrome of Holt-Oram. Cardiologia (Basel), 45, 2 I.

Zetterqvist, P. (1963). The syndrome of familial atrial septal defect, heart arrhythmia and hand malformation (Holt-Oram) in mother and son. Acta Paediatrica (Uppsala), 52, II5. 